\title{
Governança Pública em Saúde Pós-Reforma Gerencial no Brasil: Reconciliando Perspectivas para uma Análise
}

Multinível

\section{Public Governance in Post-Managerial Reform in Health in Brazil: Reconciling Perspectives for a Multilevel Analysis}

\author{
Fernanda Filgueiras Sauerbronn \\ Doutorado em Administração / Fundação Getúlio Vargas \\ Professora / Universidade Federal do Rio de Janeiro \\ http://lattes.cnpq.br/8761482881522916 \\ orcid.org/0000-0002-7932-2314 \\ fernanda.sauerbronn@facc.ufri.br
}

Resumo: O presente ensaio tem foco na governança da política pública de saúde no Brasil no contexto pós-reforma gerencial. A argumentação desenvolvida tem o objetivo de propor uma análise que considere a governança pública como formada por influências advindas de múltiplos níveis, pautada no conceito de codeterminação, como forma de reconhecer questões de economia política no processo de interação de atores públicos e privados e seus reflexos sobre a sociedade. Assim, os autores recuperam alguns aspectos históricos de pós-reforma gerencial, a introdução da competitividade administrada na política pública de saúde brasileira e revisitam três abordagens teóricas de governança pública, em busca de uma proposta para o estudo da dimensão público-privada na saúde pública. Observa-se na revisão que são raros os estudos que reconheçam a coexistência de diferentes abordagens em governança pública (seus pressupostos, possibilidades e limitações) e que procurem reconciliar seus múltiplos níveis.

Palavras-chaves: Governança Pública, Perspectivas Teóricas, Saúde Pública, Codeterminação.

Abstract: This essay focuses on the governance of public health policy in Brazil in the managerial post-reform context. The argumentation aims to propose an analysis that considers public governance as formed by influences arising from multiple levels, based on the concept of co-determination, to recognize political economy issues encompassing public and private actors, especially its impacts on society. Therefore, the authors recover some historical aspects of postmanagerial reform, the introduction of managed competition in Brazilian health policy and revisit three theoretical approaches to public governance in search of a proposal for the study of public-private dimension in public health provision. It is noted that few studies recognize the coexistence of different approaches in public governance (its assumptions, possibilities and limitations) and seek to reconcile its multiple levels.

Keywords: Public Governance, Theoretical Perspectives, Public Health, Codetermination.

Texto completo em português: http://www.apgs.ufv.br Full text in Portuguese: http://www.apgs.ufv.br

\section{Introdução}

No Brasil, a reforma do Estado iniciada em 1995 (Plano Diretor da Reforma do Aparelho do Estado, 1995), inspirou-se na reforma gerencial da Grã-Bretanha e envolveu, por um lado, a descentralização dos serviços sociais para estados e municípios e, por outro, a delimitação da atuação do Estado, com a transferência de atividades para o setor público não estatal (Bresser-Pereira, 1999, p. 6). A partir dessa particular reforma, teve início no Brasil o reconhecimento de organizações privadas e públicas não estatais como atores relevantes para o preenchimento de lacunas deixadas pelo Estado no provimento de bens públicos (Bresser-Pereira, 2010).

Entretanto, é necessário recobrar que a teoria dos bens públicos, em sua origem, apresenta o Estado como o grande provedor de bens públicos (Kaul \& Mendoza, 2003). E que, nas últimas décadas, o papel do Estado foi contestado por abordagens neoliberais as quais afirmam que a noção estatizante de bens públicos pertence a um contexto sociopolítico (e temporal) particular (Desai, 2003). Este movimento teve origem em determinados diagnósticos e prognósticos que profetizavam e demandavam uma redução inexorável e irreversível do papel do Estado na vida econômica, social e cultural (Hood, 2005). Desde então, é possível observar que uma lógica de 'quasi-mercado' (Ferlie, 2002; Mintzberg, 1996) vem dominando gradualmente o provimento de bens públicos e, consequentemente, a gestão pública, trazendo implicações para as noções de governança em torno do provimento de bens públicos (Ferlie, Lynn \& Pollitt, 2005). Ou seja, a reforma ocorrida atende a determinados ideários e princípios teóricos incompatíveis com a lógica adotada no provimento de bens públicos em diversas áreas de políticas públicas até então (Pinho, 2016).

Por exemplo, a política pública de saúde no Brasil, desde a Constituição Federal de 1988 - CF/1988 -, passou a ter como fundamento um sistema de saúde público, universal, integral, equânime, gratuito, descentralizado, hierarquizado e regionalizado (Martins et al., 2011). Entretanto, com o advento da reforma gerencial, soma-se a este quadro a criação e a regulamentação dos espaços de atuação de novos atores por meio de novas formas de contratação, advindos das Leis 9637/1998, 9790/1999 e da EC no. 29/2000 (Cabral \& Cabral, 2012). Consequentemente, tem crescido a importância do tema governança, conforme apontam alguns estudos nas áreas de saúde pública e saúde coletiva, que têm avançado sobre a economia da saúde (Piola \& Viana, 2009), dada a existência de uma dinâmica público-privada que impacta a entrega de resultados junto à sociedade (Menicucci, 2007). 
Neste sentido, o presente artigo adere à convocação feita por Bahia (2008) e Menicucci (2008) a favor de reflexões mais sistêmicas sobre as relações entre o público e o privado no âmbito da política de saúde no Brasil. O desafio proposto é mais do que teórico ou analítico, uma vez que visa revelar de forma consistente essas relações, mas também um desafio político na medida em que busca compreender as dimensões de economia política:

(...) de forma menos reducionista, que considere o conjunto do sistema de saúde e torne mais claro o papel do Estado e dos diferentes atores (...) uma reflexão teórica que supere certo impasse cognitivo subjacente aos estudos sobre a institucionalidade da assistência à saúde no Brasil (Menicucci, 2008, p. 1403).

Adicionalmente, argumenta-se que o debate sobre a governança no provimento de bens públicos frequentemente desconsidera as realidades políticas locais e os arranjos formados por diferentes atores, modelos e instrumento de ação (Sorensen, 2014). Cabe reconhecer que é no processo de interação entre diferentes atores sociopolíticos (públicos e privados) que são construídos, estabelecidos e reforçados os usos de mecanismos e lógicas de ação específicos (Stivers, 2009). Em termos epistemológicos, portanto, torna-se importante considerar a relevância do conhecimento a respeito de possíveis barganhas políticas sobre quais bens incluir no domínio público, como fazê-los acessíveis a todos e quando a produção desses bens caberá a agentes públicos ou privados (Besley \& Gathak, 2007).

Para dar conta de tal argumentação, o presente ensaio teórico apresenta uma abordagem de estudo que reconheça a coexistência das três abordagens de governança pública em saúde (seus pressupostos, possibilidades e limitações), colocando o foco sobre as práticas sociais que informam sobre: (a) as lógicas concorrentes que são moldadas em e por meio de processos que promovem a construção de significados e formas de ação compartilhados (Pedersen, Sehested \& Sorensen, 2011); (b) a construção ou manutenção de mecanismos e instrumentos de gestão das coordenações e das interdependências (Milani \& Solinís, 2002); (c) a repartição do poder entre aqueles que governam e aqueles que são governados (Smith, 2010).

Nesse sentido, o texto está estruturado nas seguintes seções: $\mathrm{Na}$ segunda seção, situamos o estudo da governança públicoprivada na saúde pública brasileira, destacando o surgimento de um novo processo de interação dos atores, ao longo da última década, e como a política de saúde deve ser considerada um relevante lócus de investigação sobre governança. Na terceira, são revisitadas três abordagens sobre governança pública identificadas na literatura de administração e ciências contábeis no Brasil e críticas de autores nacionais e internacionais a essas perspectivas. Na quarta seção, apresentamos como uma perspectiva multinível pode permitir compreender a dinâmica de interação entre os atores sociais, e a forma como estratégias cotidianas, instrumentos e mecanismos são utilizados (ou não) pelos atores, de forma a atender a determinados interesses. Adicionalmente, adentramos brevemente os aspectos metodológicos, relacionados a uma análise multinível por meio do conceito de codeterminação.

\section{Saúde, Reforma Gerencial e Novos Atores}

2.1Flexibilização para combater 'retrocesso burocrático' de 1988

Desde o advento da proposta de reforma do estado, pelo Ministério da Administração e Reforma do Estado (MARE), em 1995, o provimento de bens públicos de saúde passou a ser considerado serviço não exclusivo do Estado. Naquela oportunidade, o então Ministro Luiz Carlos Bresser Pereira destacou que a Constituição Federal de 1988 foi um 'retrocesso burocrático sem precedentes', com engessamento via ampliação da intervenção e dos controles estatais e 'sem que houvesse maior debate político' (Plano Diretor da Reforma do Aparelho do Estado, 1995, p. 21).

A classificação da 'Constituição Cidadã' como um retrocesso burocrático pode (ou deve) ser considerada como estando na contramão de um movimento de reforma sanitária universalista e participativo. Primeiro, os conselhos gestores de políticas públicas, principalmente os conselhos municipais de saúde, ganharam maior vigor e tornaram-se mecanismos viabilizadores dos princípios constitucionais de democratização e controle social (Saliba, Moimaz, Ferreira \& Custódio, 2009). Segundo, como indica Paim (2013), a CF/1998 incorporou proposições da reforma sanitária brasileira e reconheceu o dever do Estado frente ao direito à assistência social e à saúde, criando o Sistema Único de Saúde (SUS), universal, público, participativo, descentralizado e integral.

Entretanto, a contramão da reforma de 1995 não está isolada do contexto constituinte. A própria dinâmica política na época da constituinte é permeada por um desinteresse específico pela garantia dos direitos universais.

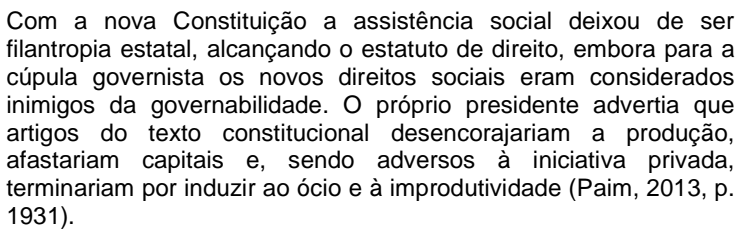

Uma releitura de outros trechos do Plano Diretor permite reconhecer associação de uma necessária reforma do Estado a uma intencional transferência de serviços sociais relevantes para prestadores de serviços privados, sob uma lógica de mercado. Assim, as soluções flexibilizadoras - antes apontadas para empresas estatais e suas subsidiárias, autarquias e fundações, e justificadas à luz de um 'retrocesso burocrático'- expandem-se sob essa mesma lógica mercadológica para setores sensíveis em termos de direitos humanos fundamentais, em nome do atendimento às crescentes demandas sociais e a busca pela eficiência:

Tornou-se, consequentemente, inadiável equacionar a questão da reforma ou da reconstrução do Estado, que já não consegue atender com eficiência a sobrecarga de demandas a ele dirigidas, sobretudo na área social. (...) o Estado tendeu a assumir funções diretas de execução. As distorções e ineficiências que daí resultaram deixaram claro, entretanto, que reformar o Estado significa transferir para o setor privado as atividades que podem ser controladas pelo mercado. (Plano Diretor da Reforma do Aparelho do Estado, 1995, p. 12) 
A reforma empreendida no sistema de saúde no Brasil, por meio da reestruturação dos núcleos do Estado, alinhou-se às justificativas reformistas dos sistemas de saúde no mundo, associadas ao 'fim do welfare state', à 'sobrecarga ingovernável' imposta aos Estados por uma política 'irreal' de distribuição de serviços públicos (Almeida, 1996, p. 4). A autora aponta que esse alinhamento implicou na adoção de uma resposta liberalconservadora por meio do modelo formulado nos EUA, no final dos anos 70, denominado "competição administrada".

\subsection{Competição administrada e a introdução de atores privados na saúde pública}

Diante desse contexto de reforma e contrarreforma, consideramos que o provimento de bens públicos em saúde no Brasil foi alterado nas últimas décadas (Bahia, 2008; Pereira, 1996) devido a três aspectos, em termos administrativos. Primeiro, há a constituição do SUS, visando à universalização do acesso, à ampliação da organização popular e à democratização da gestão (Martins, Cotta, Mendes, Priore, Franceschinni, Cazal, \& Batista, 2011, p. 1934). Segundo, a CF de 1988 viabilizou a instituição do processo de descentralização dos serviços públicos básicos mediante a definição de macro responsabilidades, em que cada área de política necessitava desenvolver os mecanismos de coordenação e cooperação (Cavalcante, 2011, p. 1786). Terceiro, e mais impactante, foi a definição do espaço de atuação para novos atores privados sem fins lucrativos, por meio da estratégia de publicização e de novas formas de contratação. A publicização expandiu-se por meio da Lei 9637/1998 e da EC 29/2000, além de leis e decretos municipais específicos surgidos desde então, que introduziram e regulamentaram a atuação das Organizações Sociais de Saúde (Alcoforado, 2010).

A combinação desses fatores introduziu no país a lógica de 'competição administrada'. Segundo esta lógica, deveriam ocorrer inovações nas formas de organização da distribuição de serviços de saúde. A atuação de grupos de pessoas e empresas poderia fornecer meios mais eficientes, o Estado deveria ser o regulador do desempenho do setor e o 'financiamento desses serviços não deveria necessariamente provir de impostos gerais' (Almeida, 1996, p. 9). Conforme aponta esta autora, o financiamento de serviços em saúde, portanto, mudaria em cada nível segundo uma relação direta entre custos e serviços prestados ou recebidos, seguindo os princípios de trocas de mercado.

A competição administrada em saúde indica a introdução de uma dinâmica política que nem sempre atende ao pressuposto universalista preconizado na CF/1988. Trata-se da incorporação de uma 'lógica concorrencial' na qual, na prática, pode-se distinguir duas modalidades básicas de concorrência: (a) as virtuais, por meio de formas de concorrência não-comerciais, por meio da comparação do desempenho, benchmarking e concorrência qualitativa de agências governamentais; e (b) as reais, presentes nas concorrências públicas, a subcontratação externa, ou o retorno à subcontratação interna (Kissler \& Heideman, 2006, p. 489). Essa concorrência na saúde pública no Brasil, assume contornos específicos, conforme apontam Santos, Ugá e Porto (2008: 1439):
Trata-se de um sistema de saúde que, embora constitucionalmente definido como universal e integral, tem o setor privado prestador sustentado pela compra estatal de serviços e um segmento de seguradoras e operadoras de planos de saúde fortemente subsidiado pelo Estado, pelos distintos instrumentos de renúncia fiscal.

Deste modo, a dinâmica de interação entre os atores na saúde pública brasileira alterou-se também em função da ampliação da atuação dos prestadores privados de serviços de saúde. A expansão da assistência privada no país está intimamente ligada a decisões governamentais prévias que, embora voltadas para a assistência à saúde de caráter público ou para a ampliação de cobertura, forneceram incentivos diretos (convênios com repasse de recursos) e indiretos (incentivos fiscais inicialmente para pessoas jurídicas e depois para físicas ou isenções de multas e redução de penalidades) para o desenvolvimento do mercado privado de saúde, tanto no aspecto da prestação de serviços quanto na gestão privada da assistência (Menicucci, 2007). O estudo de Santos, Ugá e Porto (2008, p. 1439) aponta que as desigualdades que ocorrem no sistema de saúde brasileiro devem-se ao fato de a cobertura de serviços ofertados pelo setor privado ser duplicada à cobertura do SUS e de o financiamento público ao SUS ser minoritário, ao considerar os grandes subsídios públicos para o setor privado.

Conforme indica Bahia (2008), os investimentos privados no setor e a atuação dos diversos agentes privados, favorecidos por decisões governamentais, tiveram várias consequências: (a) o estabelecimento de padrões de comportamento difíceis de reverter; (b) a estruturação dos interesses privados na saúde, condicionando o conflito político e estruturando o processo de tomada de decisões; (c) a particularização das demandas de saúde e a constituição de identidades corporativas, o que contribui para o enfraquecimento da proposta do SUS, de caráter publicista e universalista; e (d) o fortalecimento da segmentação de clientelas, reforçando a perspectiva de que ao sistema público cabe a cobertura da população mais pobre e em condições desfavoráveis de inserção no mercado de trabalho. Enfim, segundo a autora, o Estado funcionou como organizador do mercado e como agente ativo no processo de legitimação de uma segmentação.

Adicionalmente, cabe destacar que ao longo da trajetória do SUS foram construídas imagens negativas sobre a assistência pública. Estas servem como critérios para avaliação da eficácia do sistema público e, ao mesmo tempo, reforçam pressupostos e perspectivas que justificam a ação por parte dos diferentes atores (Menicucci, 2008). Essas imagens contribuem para o reforço a certos problemas que informam sobre lógicas de ação destes atores e, consequentemente, sobre a governança da saúde pública.

O SUS mostra-se, assim, um lócus privilegiado em que os interesses se organizam e as trocas entre os agentes (produtores de bens e serviços de saúde) se constroem socialmente, sendo o lugar em que a política de saúde se concretiza e se desdobra em ações públicas. Segundo Pereira (1996), o SUS é uma arena decisória tomada por diversas coalizões de grupos de interesse, a qual condensa em seu espaço a presença tanto de interesses públicos quanto privados, em razão de produzir bens e serviços que 
podem ser qualificados em duas situações distintas: bens e serviços enquanto objeto de transação no mercado e bens e serviços enquanto direito social.

A argumentação aqui proposta pretende ir além das posições dicotômicas em que de um lado encontra-se o Estado, exclusivamente como provedor dos meios que asseguram os direitos sociais (o domínio público), e de outro o mercado, oferecendo bens e serviços para serem transacionados em típicas relações de troca produtor/consumidor (o domínio privado). É necessário observar posições intermediárias proporcionadas por uma multiplicidade de formas de atuação e que considerem a diversidade social, política e cultural dos municípios brasileiros, respeitando a grande complexidade do fenômeno.

Portanto, a questão que se levanta não é se a dinâmica públicoprivada é boa ou ruim, mas sim reconhecer que ela é uma realidade na saúde pública brasileira e investigar suas práticas e seus reflexos sobre a sociedade, principalmente, em termos de governança pública. Por esse motivo, torna-se relevante compreender como o tema governança pública tem sido tratado na literatura nacional e internacional, bem como as possibilidades e limitações para futuros estudos sobre a dinâmica público-privada na saúde pública brasileira.

\section{Abordagens sobre Governança Pública (GP)}

O conceito de governança pública (GP) vem despertando interesse entre acadêmicos da área de administração e ciências contábeis no Brasil. Um levantamento na base de dados Spell (www.spell.org.br) indica a publicação, desde 1995, de noventa artigos em periódicos da área, contendo em seu resumo a expressão "governança pública". Dentre estes, constatou-se a existência de, pelo menos, três abordagens ao tema, que consideram a governança pública como: "governança corporativa no setor público", "governança de redes de políticas públicas", "governança global para o desenvolvimento". Procuraremos na presente seção esclarecer essas correntes para dar sustentação a outra proposta de investigação.

\subsection{GP como 'governança corporativa no setor público'}

Os estudos sobre governança em administração e ciências contábeis são marcados pela influência da teoria da agência (Jensen \& Meckling, 1976), no âmbito da governança corporativa. Esta abordagem está associada à necessidade de redução de assimetria informacional entre agente-principal, sendo a necessidade de monitorar o comportamento dos agentes que explica a demanda pela contabilidade e, principalmente, pela construção de instrumentos de governança corporativa (Martinez, 1998, p. 9).

Nesta perspectiva, o controle principal-agente seria suficiente para controlar o comportamento oportunista dos agentes, vistos segundo a perspectiva do homo economicus como maximizadores de ganhos individuais em detrimento dos interesses do principal (Sauerbronn \& Faria, 2011). Portanto, os conselhos de administração, os relatórios gerenciais, bem como os pareceres de auditoria, tornam-se os meios pelos quais as partes contratantes governam (mensuram e monitoram) a execução dos objetivos contratuais (Slomski, 2007). Consequentemente, segundo a Comissão de Valores Mobiliários (2002), a governança corporativa seria um conjunto de práticas visando a aperfeiçoar o desempenho e protegendo as partes interessadas no negócio, por meio de transparência, equidade de tratamento, prestação responsável de contas e conformidade no cumprimento de normas reguladoras.

Em uma perspectiva funcionalista, há de se reconhecer, conforme aponta Avelar (2012, p. 121), que a governança corporativa é uma forma de reorganização burocrática por promover a readequação dos instrumentos burocráticos, para atender as necessidades homeostáticas dos sistemas organizacionais face a dinâmica em seus ambientes. Para o autor:

A governança reinterpretou a impessoalidade da burocracia de Weber, nas relações entre as partes interessadas, por meio do princípio fairnessou senso de justiça (...) A formalidade burocrática das comunicações aparece na governança em seus princípios de transparência (disclosure) e prestação de contas (accountability) e na necessidade imprescindível de organizar, subdividir, disciplinar e supervisionar o trabalho de dezenas de pessoas (...) Depois de identificado esse conflito [de agência], a governança foi idealizada para resolver uma disfunção burocrática, que resultou de uma necessidade de adequação do sistema de gestão, a uma nova dinâmica organizacional. (Avelar, 2012, p. 127).

No Brasil, os estudos sobre governança pública em administração e ciências contábeis quase sempre se vinculam à abordagem da governança corporativa aplicada ao setor público (Marques, 2007; Matias-Pereira, 2010). Consequentemente, os estudos mantêm-se relacionados à adoção de medidas para mensurar transparência, corrupção e ineficiência no uso de recursos públicos, em organizações governamentais e não governamentais (Benedito, Guimarães, Pereira, \& Andrade, 2013; Cavalcante \& Luca, 2013).

Em termos históricos, a normatização da governança pública encontra um importante marco no Cadbury Report que, influenciado pelo Nolan Report, identificava três princípios fundamentais de governança corporativa: transparência, integridade e responsabilidade em prestar contas (Slomski, Mello, Tavares, \& Macedo, 2008, p. 121). Segundo os autores, os referidos relatórios serviram de base para que o Instituto Britânico de Finanças e Contabilidade Pública (CIFPA), em 1995, desenvolvesse a primeira estrutura de governança corporativa aplicada ao setor público.

A abordagem da governança corporativa aplicada ao setor público ganhou destaque em países anglo-saxões, como Austrália, Canadá, Estados Unidos, Nova Zelândia e Reino Unido, associada à agenda do New Public Management (Mello, 2006). A Federação Internacional de Contadores (IFAC), através do Comitê Setor Público (PSC), publicou em 2001, o estudo 13, com a finalidade de orientar os administradores públicos e a sociedade sobre princípios e práticas da boa governança. No ano de 2014, o Tribunal de Contas da União (TCU) lançou o Referencial Básico de Governança Aplicável a Órgãos e Entidades da Administração Pública, alinhando a essa perspectiva suas proposições, seus instrumentos e recomendações práticas (TCU, 2014).

Conforme sintetiza Marques (2007), para se alcançar uma efetiva governança corporativa na administração pública, seriam demandados instrumentos de gestão e controle, baseados em 
liderança, responsabilidade, integridade, compromisso e transparência. Estes fundamentos servem de base para a recomendação de construção de estratégias, sistemas, políticas e processos que, segundo Slomski et al. (2008, p. 141), desdobramse em instrumentos relacionados a: responsabilidade estatutária; responsabilidade pelo dinheiro público; comunicação com as partes interessadas; papéis e responsabilidades visando equilíbrio de poder e autoridade; política de remuneração; controle e gestão de risco; auditoria interna; controle interno; orçamento; administração financeira; relatórios externos; medidas de desempenho (economia, eficiência, efetividade e conveniência); e auditoria externa.

O IFAC 13 reforça a ênfase sobre a construção e uso de instrumentos que permitam a gestão e o controle do comportamento do agente individual e, consequentemente, uma boa governança pública. Portanto, os estudos nacionais que adotam essa perspectiva consideram que a transparência (junto ao principal) dos atos do administrador público (ou do agente) pode ser obtida por meio dos instrumentos de controle e prestação de contas públicas, minimizando os problemas de agência e a assimetria informacional, portanto, melhorando a governança (Cavalcante \& Luca, 2013; Silva, Pessoa, Batista \& Scaccabarozzi, 2011).

Algumas críticas indicam que esta abordagem carece de teorias de Estado e sociedade, bem como de outras teorias organizacionais, uma vez que simplifica complexas relações no contexto de provimento de bens públicos àquelas entre agente e principal pensadas no âmbito da teoria da firma (Sauerbronn \& Faria, 2011; Sorensen, 2014; Stivers, 2009; Stoker, 1998).

As críticas apontam que a governança pública não se limita à separação propriedade-controle que sustenta e justifica uma relação agente-principal. Os agentes podem ser responsáveis junto a um grande número de partes interessadas dentro e fora das organizações, considerando o contexto da política pública. Dada a heterogeneidade e a complexidade dos interesses em jogo no setor público, os agentes tendem a optar por estratégias e metas ambíguas que sejam menos propensas a serem rejeitadas pela sociedade (Grossi, 2013).

\subsection{GP como 'governança da rede de políticas públicas'}

Tradicionalmente, em administração pública, o termo governança significava apenas "governar sistemas políticos" (Procopiuk, 2013, p. 172). O Estado-nação era o único responsável pelo planejamento, execução e avaliação de políticas públicas, de forma centralizada e de cima para baixo, com uma perspectiva estadocêntrica (Andion, 2012). Esta perspectiva foi atacada pela agenda do New Public Management e justificada frente à crise do Welfare State e necessidade de diminuição do aparelho do Estado em diversas áreas de política (Hood, 2005; Stoker, 1998).

Governança, então, passou a significar um novo modo de governar, mais pluralista, cooperativo e descentralizador, menos hierárquico e centralizador (Andion, 2012). Passou a existir a preocupação com a capacidade de orientar a formulação e execução de políticas públicas com o envolvimento de diversas instituições. Nesta concepção, agentes públicos, semipúblicos e privados participam e cooperam formando uma rede de políticas públicas (Smith, 2010).

Segundo Stoker (1998, p. 18), há cinco proposições nas quais a governança:

- Refere-se a um conjunto de instituições e atores que são invocados do próprio governo, mas também além deste.

- Aponta a indefinição de fronteiras e responsabilidades para tratar de questões sociais e econômicas.

- Identifica a dependência de poder envolvida nas relações entre as instituições envolvidas na ação coletiva.

- Envolve redes de atores autônomas e autogovernáveis.

- Reconhece que a capacidade de fazer as coisas não repousa sobre o poder do governo para comandar ou usar a sua autoridade. Ela vê o governo como capaz de usar novas ferramentas e técnicas para orientar e guiar.

Portanto, a abordagem de 'governança por meio de redes de políticas públicas' reconhece que a condução das políticas passa a ser feita conjuntamente por atores do mercado, da sociedade civil e do aparelho do Estado (Kooiman, 1993). Na perspectiva do autor, as redes estruturariam ou criariam uma ordem que não pode ser imposta, mas que é resultado da interação de uma multiplicidade de atores. Segundo Rezende (2008), seria um modelo "pósburocrático" fundamentado em modelos descentralizados, com grande flexibilidade para gerir e garantir a provisão dos bens públicos.

O modelo de descentralização de políticas públicas brasileiro, aprofundado no PDRAE em 1995, apresenta a governança como central para a estruturação das relações entre o Estado (nos níveis federal, estadual e municipal), as organizações privadas (com e sem fins lucrativos) e os atores da sociedade civil (Arretche, 2003; Secchi, 2009).

A noção de governança torna-se ainda mais complexa quando envolve organizações da sociedade civil, devido à existência de: a) autonomia/dependência em termos financeiros, materiais e tecnológicos; b) legitimidade de seus objetivos e atuação no contexto local; c) validade da ação - informação, mobilização, normatização, operação e execução de políticas sociais (Santos \& Carrion, 2011).

Entretanto, pairam dúvidas sobre a capacidade de articulação de diversas redes por parte dos diversos entes estatais; sobre o pressuposto de neutralidade da rede e as bases de cooperação entre esses atores; e também sobre seus resultados. Para Kissler e Heidemann (2006, p. 488), o 'número excessivo de parcerias não é mais administrável pelos municípios', devido ao fato destes não possuírem meios suficientes para garantir uma gestão participativa e de dar transparência nas relações entre as sociedades de capital e os órgãos de governo.

Soma-se a este argumento a crítica de Stivers (2009). A autora considera que a visão "pós-burocrática e flexível" das redes mostrase frágil em termos conceituais:

A imagem da rede é algo como um 'Tinkertoy "ii : as organizações são os pequenos discos e os mecanismos de colaboração (pechinchas, negócios, trocas, interesses, contratos, protocolos, e assim por diante) são as varas que mantêm as organizações juntas. Este 
quadro torna praticamente impossível conceituar adequadamente como a colaboração é realmente realizada. Redes acabam parecendo congeladas e rígidas como as hierarquias que se destinam a substituir. (Stivers, 2009, p. 1098)

Diante dessas críticas, o estudo da governança pública deveria permitir reconhecer as consequências e os efeitos colaterais da estruturação de relações (não neutras e conflituosas) entre Estado e demais atores sociais no provimento de bens públicos (Sorensen, 2014). Segundo a autora, há nos estudos sobre governança uma tendência para ignorar o papel dos conflitos nos processos de coordenação ou de vê-los como uma força destrutiva passível de ser modificada ou neutralizada.

Segundo Pedersen et al. (2011), tradicionalmente, a capacidade de promover governança pública foi vista como dependente da presença de um modelo institucional (ou funcional) coerente de coordenação que segue uma lógica racional e proporciona uma combinação de formas verticais e horizontais de coordenação entre atores públicos e privados. Uma compreensão teórica tradicional de coordenação deveria ser gradualmente substituída por novas teorias que a vejam como o resultado de um processo pluricêntrico confuso que envolve diversas lógicas interpretativas de ação, endogenamente construídas, que se conectam por arenas interativas 'loosely coupled' (p. 376). De acordo com esta visão, a coordenação está ocorrendo em um terreno caracterizado por lógicas concorrentes que são moldadas em (e através de) processos que promovem a construção compartilhada de significados e de formas de ação.

\subsection{GP como 'governança global do desenvolvimento'}

Uma terceira abordagem coloca ênfase sobre a questão do desenvolvimento, porém distante de seu objetivo comum de crescimento econômico. Conforme indica Moloney (2009, p. 611), desenvolvimento socioeconômico pode e deve ser adequadamente garantido e monitorado por meio de uma "agenda de governança". Essa agenda é apresentada, dentre outros documentos, pelos relatórios do Banco Mundial, denominados Gerenciando o Desenvolvimento: As Dimensões de Governança e do relatório Além do Consenso de Washington: Instituicões Importam (p. 612). Conforme indica Secchi (2009, p. 357-358),

Os chamados teóricos globalizadores (globalizers), de tradição liberal, veem governance como a derrocada do modelo de relações internacionais vigente desde o século XVII, onde o Estado-nação sempre foi tido como ator individual, e a transição a um modelo colaborativo de relação interestatal e entre atores estatais e não estatais na solução de problemas coletivos internacionais. Governança, nesse sentido, denota o processo de estabelecimento de mecanismos horizontais de colaboração para lidar com problemas transnacionais como tráfico, terrorismo e emergências ambientais.

O estabelecimento de "boas práticas" de governança e de mecanismos de mensuração passaram a ser necessários para viabilizar e justificar iniciativas de cooperação para o desenvolvimento, fomentadas por organismos internacionais (Grossi, 2013). Neste sentido, foi criado pelo Banco Mundial o Worldwide Governance Indicators (WGI), atendendo particularmente aos modelos idealizados por organizações internacionais como a ONU ou a OECD (Kaufmann, Kraay, \&
Matruzzi, 2007). O conjunto de indicadores agregados baseou-se em centenas de variáveis individuais específicas e desagregadas, que seriam responsáveis por medir várias dimensões de governança. O WGI utiliza seis dimensões de governança em seu cálculo: voz e responsabilização, estabilidade política e ausência de violência, eficácia governamental, qualidade regulatória, estado de direito e controle da corrupção (Kaufmann et al., 2007).

Consequentemente, ganhou força nas últimas décadas uma abordagem à governança pública que a apresenta como um conjunto adequado de práticas democráticas e de gestão pública (GROSSI, 2013). "Boa governança" seria então uma combinação de "boas práticas" de gestão pública (eficiência administrativa, accountability democrática e combate à corrupção), consideradas pré-requisitos para que países em via de desenvolvimento recebam recursos econômicos e apoio técnico (Secchi, 2009, p. 358).

A boa governança é importante para os países em todos os estágios
de desenvolvimento. Nossa abordagem é concentrar-se nos
aspectos de boa governança que estão mais estreitamente
relacionados com a nossa vigilância sobre as políticas
macroeconômicas, ou seja, a transparência das contas públicas, a
eficácia da gestão dos recursos públicos, bem como a estabilidade
e transparência do ambiente econômico e regulatório para atividade
do setor privado (IMF, 2003, p.1).

Conforme apontam Souza e Carrion (2011, p. 1851), nas formas tradicionais de cooperação internacional para o desenvolvimento, os objetivos e métodos de trabalho tendem a serem impostos pelo país ou agência (do Norte) que oferta os recursos financeiros ao país menos desenvolvido (do Sul), havendo um acordo marcado por interesses do primeiro sobre o segundo. Nas concepções mais modernas, ainda segundo as autoras, existiria certa "acomodação" entre doadores e receptores de forma que todos pudessem trabalhar em "parceria" na definição dos projetos, de seus instrumentos de gestão e de governança. Esta nova forma de governança global do desenvolvimento seria fundamentada em ações que governos e organizações da sociedade civil de países distintos planejam e executam, objetivando fomentar um desenvolvimento mais "equilibrado e justo" no mundo (Souza \& Carrion, 2011). Conforme apontam Simão, Guedes e Nieto (2017), as sucessivas tentativas de intervenções externas, frequentemente, resultam em fraca governança e gestão pública, como revelam no estudo sobre o neocolonialismo em Angola.

Assim, diversas críticas são traçadas à perspectiva que aqui denominamos de "governança global do desenvolvimento". Primeiro, de que a metodologia do WGI carece de evidências que validem o construto, pois os indicadores não apresentam hipóteses sustentadas nas diferentes realidades locais e nos complexos arranjos de políticas públicas (Thomas, 2010). Para o autor, os indicadores são apresentados como medindo a governança em si, quando na verdade mensuram apenas uma "percepção" de governança (Thomas, 2010, p. 37). Segundo, a abordagem é criticada por não problematizar adequadamente os interesses dessas organizações internacionais em definir uma agenda de governança pública em temas globais, desconsiderando contextos e realidades locais, visando ao atendimento de concepções e propósitos específicos de uma determinada cooperação 
internacional para o "desenvolvimento" (Grossi, 2013). As críticas destacam, nas diferentes áreas de política pública, a tentativa de estabelecer uma agenda comum de provimento de bens públicos em termos globais (Bartley, 2011; Besley \& Ghatak, 2007; Kaul \& Mendoza, 2003).

Algumas críticas bastante contundentes advêm dos estudos de economia política internacional. Para esses autores, essa governança global envolve práticas e relações de poder exercidas por redes de atores de diferentes nacionalidades e com interesses específicos - tais como corporações e instituições transnacionais, autoridades governamentais, altos executivos, acionistas de empresas, organizações não governamentais e instituições locais. São exemplos dessa crítica os estudos, na área de administração e contabilidade, no Brasil, realizados por Fontoura e Guedes (2013) e por Rampazo, Ichikawa e Carrieri (2014).

Portanto, há que se considerar também o papel significativo atribuído às grandes corporações em diferentes iniciativas de cooperação internacional para resolução de problemas públicos, por meio de ações de Responsabilidade Social Corporativa (Blowfield, 2005; Frynas, 2008). Segundo autores como Barley (2007) e Bartley (2011), a busca pela garantia do atendimento de interesses privados relacionados a questões públicas trazem importantes reflexos para a noção de governança no contexto da globalização.

Estas críticas deixam claro que governança pública não é simplesmente um fenômeno no nível microindividual (entre agenteprincipal), ou de cooperação entre diferentes atores envolvidos na rede política pública, no nível meso-organizacional. Segundo Smith (2010), os estudos devem considerar a governança também como um fenômeno que releva "quem governa" e "com quais interesses" em termos macroestruturais. Decerto, o estudo da governança deve, principalmente, reconhecer a existência de uma dinâmica público-privada que é influenciada por esses diferentes níveis de análise em termos internacionais (Bartley, 2011).

\section{Uma proposta de análise multinível}

O presente ensaio procura transcender individualmente cada uma das abordagens à gestão pública (GP) apresentadas anteriormente, reconhecendo seus pressupostos, suas possibilidades e limitações. Procuramos destacar na revisão apresentada a dimensão de economia política, de natureza públicoprivada, que demarca a gestão pública contemporânea. Esta proposta, portanto, alinha-se a uma perspectiva mais plural que reconhece a multiplicidade de atores, entretanto, sem pactuar com o pressuposto de neutralidade e cooperação entre eles. Busca-se compreender a noção de governança em contextos cujos impactos sobre a sociedade mostram-se condicionados aos interesses dos múltiplos atores envolvidos e das lógicas de ação socialmente construídas.

A abordagem proposta no presente ensaio sustenta-se no fato de que estudos mais plurais devam considerar governança como a totalidade das diversas maneiras pelas quais os indivíduos e as instituições, públicas e privadas, administram seus problemas comuns. Ou seja, considera-a como um processo contínuo que envolve interesses e ações conflitantes e cooperativas. Consequentemente, essa proposta de estudo sobre a dinâmica público-privada deve debruçar-se sobre contextos nos quais as instituições públicas não mais ofereçam os serviços públicos, em termos exclusivos. Trata-se de contextos nos quais o Estado, simultaneamente, transfere ações para o setor privado, age em parceria com agentes sociais, e torna-se coprodutor do bem público, mas ainda na condição de responsável último pelos resultados junto à sociedade, como sugerem Kissler e Heidemann (2006).

É no processo de interação entre os diferentes atores que se materializam seus interesses, ações estrategicamente orientadas e mecanismos de gestão e controle de resultados que, em médio e longo prazo, modificam as relações (e regulamentações) originalmente pensadas (Sauerbronn \& Faria, 2011). Conforme apontam Barbosa, Tardivo e Barbosa (2016), a aprovação da Lei Complementar (LC) no 141, além de consolidar a participação orçamentária obrigatória dos entes, estabelece normas de fiscalização, avaliação e controle das despesas com saúde. A expectativa, para os autores, é de que os mecanismos de controle da gestão proporcionem a observação, a mediação e a avaliação contínua do processo, e se constituam em ferramentas estratégicas de promoção da cidadania em saúde e de produção de informações que subsidiem a tomada de decisão, contribuindo para o fortalecimento do SUS e para a defesa do direito à saúde.

Decerto, os instrumentos de gestão e controle adotados (ou não) no processo de provimento dos serviços de saúde trazem implicações para o alcance de resultados de política pública em um contexto gerencialista (Barbosa et al., 2016). É necessário ampliar a compreensão sobre as diversas dimensões sociais, políticas e culturais que direcionam a adoção ou não desses instrumentos. Porém, essas dimensões tornam-se ocultas ou de difícil alcance quando estudadas isoladamente (Sorensen, 2014).

Conforme aponta Stivers (2009, p. 1095), ontologias e epistemologias alternativas podem possibilitar aos pesquisadores a adoção de novos pontos de vista sobre a realidade da política pública e que melhor forneçam suporte para a governança democrática. Para a autora, modelos de governança centrados na racionalidade dos atores e que neguem a política democrática e o engajamento cívico podem falhar em seus próprios termos.

Argumentamos a favor do reconhecimento das possibilidades e limitações das três abordagens de governança pública para que se compreenda a dinâmica público-privada. Por influência da abordagem da "GP como Governança Corporativa", há que se reconhecer os instrumentos de controle criados e como estes são utilizados pelos atores públicos e privados (de acordo com seus interesses e motivações) e suas vantagens e desvantagens no uso. Por influência da abordagem da "GP como Governança da Rede de Políticas Públicas", há que se considerar o complexo arranjo de organizações no processo de formulação e implementação de políticas públicas no Brasil e, principalmente, as lógicas de ação dos atores privados e públicos em questão, e como estes direcionam o provimento de bens públicos junto à sociedade. Por influência da abordagem da "GP como Governança Global do Desenvolvimento", 
há que se considerar a existência de uma agenda de cooperação internacional em torno do provimento de bens públicos (sustentadas por diagnósticos, projetos e indicadores específicos), sendo necessário compreender os interesses relacionados à agenda internacional e o engajamento ativo de atores privados e públicos no contexto local.

Portanto, os aspectos a serem evidenciados nesta proposta seriam associados ao processo de interação social, no qual as práticas informam sobre: (a) as lógicas concorrentes que são moldadas em, e através de, processos que promovem a construção de significados e formas de ação compartilhados (Pedersen et al., 2011); (b) a construção ou manutenção de mecanismos e instrumentos de gestão das coordenações e das interdependências (Milani \& Solinís, 2002); (c) a repartição do poder entre aqueles que governam e aqueles que são governados (Smith, 2010).

Ao direcionar essa proposição ao estudo da governança da saúde pública torna-se premente reconhecer que a ação dos atores públicos e privados forma um conjunto de práticas sociais em curso e que se desenrolam em contextos e processos específicos (Sauerbronn \& Faria, 2011).

Buscou-se emprestado em Child (1997) o conceito de codeterminação, para propor uma perspectiva que reconheça a formação das práticas sociais a partir de múltiplas influências e que acabam por "governar as políticas públicas". Segundo Sauerbronn e Faria (2011), há razões históricas que levaram a área de administração e ciências contábeis a favorecer o nível de análise individual nos estudos que trabalhem com os conceitos de agência, redução de assimetria informacional e governança. Consequentemente, podem existir dificuldades nos estudos em governança em adotar abordagens que reconheçam de forma distinta a relação entre indivíduo, organização e ambiente.

Grande parte da literatura privilegia uma representação específica de organização e gerência (isto é, a grande corporação e o capitalismo gerencial controlado por uma 'mão visível' permitiu gerar, ao longo das últimas décadas, falsas dicotomias micro/macro, voluntarismo/determinismo), tornando escassos ou inexistentes os estudos que reconheçam a codeterminação de múltiplas dimensões. (Sauerbronn \& Faria, 2011, p. 50)

Ao recobrar a discussão sobre poder e política, Clegg e outros autores (2006) chamaram a atenção dos estudos para outros atores e grupos internos que possuem poderes para influenciar politicamente as ações. Estas são formadas pelas escolhas dentre possíveis alternativas, envolvendo o uso de poder pelas redes internas, interagem em termos de "proatividade e reação" ao longo de processos. Os atores individuais e organizacionais não se adaptam passivamente às circunstâncias que encontram nas organizações, tampouco apenas usam essas circunstâncias em escolhas voluntaristas; eles usam poder para moldar regras e combinar recursos que são coletivamente estabelecidos e negociados (Clegg, Courparsson,\& Phillips, 2006). Tanto indivíduos quanto grupos de indivíduos avaliam alternativas de ação e levam em consideração as consequências de suas ações. Essas consequências podem ser condicionadas por fatores como conhecimento, compreensão e preferências anteriores, que entram como informações relevantes para reflexão e ação.
O conceito de codeterminação (Child, 1997; Child \& Rodrigues, 2011) abriu espaço para reconhecer que as organizações são atores políticosiii e não apenas sistemas naturais ou racionais, conforme propuseram os teóricos clássicos e neoclássicos. A codeterminação viabilizaria reconhecer que a governança é um produto de ações realizadas simultaneamente por indivíduos, grupos formais e informais, internos e externos à organização, bem como outras organizações nacionais ou internacionais.

Trata-se de reconhecer a governança como uma dinâmica que "coevolui" em função das diversas interações que se estabelecem entre os atores ao longo do tempo. De acordo com a proposição dos autores, a codeterminação contemplaria aspectos que não são previamente determinados ou condicionados (por isomorfismo ou seleção natural), mas sim apenas pré-determinados em termos econômicos, sociais, culturais e políticos, existindo sempre o espaço para uma pluralidade de possibilidades de ação (racional ou intuitiva), em função dos processos e dos contextos de elevada complexidade (Child \& Rodrigues, 2011, p. 803). Esta perspectiva permite:

Saber como as possibilidades de ação disponíveis são moderadas pelo poder que os atores organizacionais desfrutam frente a outros grupos ou unidades relevantes em um ambiente multifacetado (...) adotar uma definição do poder como a capacidade de induzir as pessoas, grupos ou organizações para fazerem o que de outra forma teriam optado por não fazer, ou impedindo-os de fazer o que eles teriam escolhido fazer (...) reconhecer vários tipos de poder que vão desde a posse de recursos materiais que são valorizados por outros até a capacidade de exercer influência devido à experiência, reputação ou articulação de discurso persuasivo (Child \& Rodrigues, 2011, pp. 805-806)

Portanto, propõe-se nesse ensaio teórico que os estudos reconheçam - baseados no conceito de codeterminação - que a governança é resultante de processos de interação horizontal e vertical, envolvendo mecanismos, atores e lógicas de ação que residem nos níveis microindividual, meso-organizacional e macroestrutural. O conceito de codeterminação permite uma "análise estratificada" da governança, que pode ser observada e descrita quanto às influências que residem em diferentes níveis (Smith, 2010). A análise dos diferentes níveis deve ser realizada a partir de dimensões e categorias de análise que são discutidas nas diferentes abordagens de governança, especialmente aquelas que reconhecem questões de poder.

Em uma análise estratificada, o nível macroestrutural envolve dimensões formais, relacionadas ao contexto econômico, social e político, como leis, decretos, normas e portarias; bem como a dimensão informal, por meio de regras e normas socialmente construídas e aceitas internacionalmente para o desenvolvimento de política pública de saúde. A análise deve desafiar a visão determinista de ambiente como estrutura social que restringe a agência de gestores, organizações e grupos. Por meio desta análise, no contexto da saúde pública no Brasil, é possível desafiar os pressupostos de "superioridade do mercado" (Bahia, 2008) e também o pressuposto de "incapacidade" de organizações, gestores ou praticantes locais para influenciarem ou moldarem a "estrutura" (Bartley, 2011).

No nível meso-organizacional, torna-se necessário e possível considerar as influências organizacionais em favor das decisões 
individuais (Child, 1997). Os autores destacam que as situações de escolha entre alternativas de ação envolvem indivíduos informados por diretrizes da organização formalmente descritas e, até mesmo, por prioridades negociadas por grupos internos e pessoas em diferentes posições hierárquicas. Isto implica em investigar questões relacionadas a políticas e objetivos organizacionais deliberadamente formulados; noções de hierarquia e participação; regras e normas formais e informais; critérios e disputas que permeiam, por exemplo, a coordenação de atividades e a alocação de recursos organizacionais (Carter, Clegg \& Kornberger, 2010). O estudo das influências do nível meso-organizacional deve considerar os mecanismos e instrumentos de gestão intra e interorganizacional criados tanto para se alcançar accountability (prestação de contas, transparência e responsabilização), quanto para se obter melhor coordenação na "rede de políticas públicas".

Já no nível microindividual, reconhecemos o "monitoramento reflexivo" (Giddens, 2003, p. 6) a partir do qual gestores não só controlam e regulam continuamente o fluxo das atividades como também monitoram rotineiramente aspectos sociais e físicos dos contextos em que atuam. A racionalização da ação significa que os gestores mantêm, em termos cognitivos, um contínuo entendimento das bases complexas de sua atividade e das prováveis reações dos outros atores (Child \& Rodrigues, 2011).

Eles [os gestores] estão em uma posição para reduzir a complexidade ambiental através das suas próprias iniciativas diretas e podem ser obrigados a confiar na orientação não-racional para a tomada de decisões, como intuição. Na medida em que a utilidade da informação externa depende de uma interpretação particular e local, torna-se privilegiada uma organização que é capaz de acessar redes relacionais locais (Child \& Rodrigues, 2011, p. 808).

Portanto, devem ser investigadas dimensões individuais correspondentes, como por exemplo: origem e formação dos decisores; familiaridade e experiência em processos de formulação de políticas públicas; trajetória e posição política; cargo(s) ocupado(s); e padrões pregressos de interação com outros indivíduos e grupos internos e externos à organização (Clegg et al., 2006). Estas considerações são relevantes para que, como sugerem Sauerbronn e Faria (2011), possamos superar as posições dicotômicas simplificadoras que consideram os indivíduos ora como meros reprodutores de ações externamente determinadas e sob as quais não possuem agência, ora como agentes voluntaristas pautados em comportamento oportunista e assimetria informacional.

Neste sentido, é necessária uma orientação processual e histórica (Pettigrew, 1992 e 2012), a fim de explicar a distinção e a singularidade de determinadas ações, sob uma perspectiva diacrônica, e as influências dos diferentes níveis de análise para a compreensão do processo de interação social entre os diferentes atores envolvidos na prestação de serviços públicos de saúde. Por meio de explicações e descrições diacrônicas produzidas por atores sociais, é possível revelar a relação entre ação e influências à medida que eles se desenrolam no tempo. Em paralelo, propõe-se manter 0 interesse na historicidade do contexto social que permeiam as ações dos diferentes atores e o uso de instrumentos de gestão e controle que impactam noções de governança.
Sugere-se que, na análise da interação público-privada, sejam utilizados diferentes métodos de coleta de dados para garantir acesso às informações sobre ações e interesses dos diferentes atores (Bryman, 1989). Propõe-se, adicionalmente, a realização de entrevistas narrativas, envolvendo dimensões de passado, presente e futuro de forma a recontar o processo de interação (Jovchelovitch \& Bauer, 2000).

Dentre um universo de profissionais que atuam em organizações públicas, privadas e não estatais, sugere-se um recorte espacial. Por exemplo, alguns municípios específicos onde exista a atuação de conselhos municipais, secretarias de Estado, organização sociais de saúde, organizações filantrópicas, organizações privadas. Sugere-se selecionar os entrevistados em função de sua atuação nas organizações, de seu contato com os instrumentos de gestão e controle, de sua interação com as demais organizações públicas e/ou privadas que atuam na prestação dos serviços públicos de saúde no município.

Adicionalmente, sugere-se uma pesquisa documental para superar a "distância entre políticas e práticas oficiais e não oficiais", normalmente capturadas em entrevistas (Bryman, 1989). Devem ser coletados e analisados documentos sobre processo, contexto e conteúdo (Pettigrew, 2012) que apontem o uso de instrumentos de gestão e controle, tais como: atas de reunião, relatórios anuais, relatórios de tribunais de contas e documentos de pesquisas desenvolvidos por outras instituições e centros de estudo. Podem ser pesquisados também pareceres de tribunais de contas sobre relatórios de organizações sociais, órgãos governamentais, associações e sindicatos.

Espera-se que a presente proposta auxilie os pesquisadores na investigação da governança, por meio da composição das redes de relações e poder entre os diferentes atores nacionais e internacionais, bem como do uso de instrumentos de gestão e controle, que direcionam, dirigem e limitam o provimento de bens públicos na área de saúde.

\section{Considerações Finais}

Os autores desenvolveram ao longo do presente ensaio um argumento que explicita o fato de que as diferentes abordagens de governança ao provimento de bens públicos, frequentemente, desconsideram as realidades políticas locais e os arranjos formados por diferentes atores, modelos de gestão e instrumento de controle, principalmente, aqueles afeitos à dinâmica público-privada.

Para tal, os autores revisitaram três abordagens à governança pública que têm sido tratadas (algumas ainda timidamente) na literatura de administração e ciências contábeis no Brasil. O objetivo foi o de apresentar uma abordagem que permita o estudo da dinâmica público-privada e, ao mesmo tempo, reconhecer a coexistência das três abordagens de governança pública. As abordagens foram apresentadas quanto aos seus pressupostos, às suas possibilidades e limitações, de forma a integrá-las em uma proposta que colocasse foco sobre as práticas sociais dos diferentes atores que atuam na implementação de políticas públicas. 
Para os autores, a governança ocorre no processo de interação social entre diferentes atores públicos e privados que constroem, transformam e sustentam o uso de instrumentos e lógicas de ação. Neste sentido, foi proposto que governança passe a ser compreendida como um processo complexo e flutuante que envolve ações (co)ordenadas de diversos atores em arenas interativas, as quais promovem a comunicação entre uma pluralidade de lógicas interpretativas e práticas situadas.

Em termos epistemológicos, portanto, os autores destacaram a relevância de revelar um conhecimento (oculto) a respeito de possíveis barganhas políticas sobre quais bens incluir no domínio público, como fazê-los acessíveis a todos e quando a produção desses bens caberá a agentes públicos ou privados. Adicionalmente, os autores apresentaram os desdobramentos teórico-metodológicos, fundamentados no conceito de codeterminação, visando a uma análise multinível das práticas sociais, a qual informe sobre: (a) as lógicas concorrentes moldadas em processos que promovem a construção de significados e formas de ação; (b) a construção ou manutenção de mecanismos e instrumentos de gestão das coordenações e das interdependências entre esses atores; (c) a repartição do poder entre aqueles que governam e aqueles que são governados. Foram também discutidas brevemente as dimensões de análise nos níveis microindividual, meso-organizacional e macroestrutural, sustentando-se nas contribuições advindas das três abordagens de governança revisitadas.

Espera-se que o presente ensaio teórico auxilie pesquisadores interessados no estudo da governança em saúde. Desde a reforma gerencial, no final dos 90 , novos atores foram incorporados com a lógica da "competição administrada" no processo de provimento dos serviços de saúde, com mecanismos e incentivos que atendem (mesmo que parcialmente) aos interesses de grupos específicos. A literatura revisitada e apresentada ao longo do texto revela a crescente influência dos interesses privados na determinação do provimento dos bens públicos. Assim, a complexidade do SUS torna-o um lócus privilegiado para análise das práticas sociais que informam sobre os interesses dos atores públicos e privados, por meio dos processos de interação social no qual a política de saúde se concretiza e se desdobra em ações públicas.

Considera-se que a presente proposta de investigação, aqui especificamente dirigida à área de saúde, possa ser utilizada e ampliada também por pesquisadores dedicados aos estudos em outras áreas de políticas públicas. Decerto, inúmeros são os fenômenos do campo de públicas que mereceriam investigações por abordagens mais dinâmicas em termos políticos, ao considerarmos a perspectiva de Lindblom (1959; 1979) na qual as políticas públicas precisariam incorporar outros elementos à formulação e análise, discutindo o papel das eleições, das burocracias, dos partidos e dos grupos de interesse, indo além das questões de racionalidade e desempenho. Uma análise multinível sobre a governança público-privada mostra-se também pertinente, por exemplo, à política de educação superior no Brasil, ao se reconhecer a evolução da política em termos sócio-históricos e, principalmente, os programas, mecanismos e critérios de incentivo (relacionados a determinados atores públicos e privados) criados nas últimas décadas (REUNI, PROUNI, FIES, dentre outros). O estudo da governança público-privada em outras áreas de provimento de bens públicos mostra-se, portanto, também relevante e pertinente contemporaneamente.

\section{Referências Bibliográficas}

Almeida, C. (1996). Os Modelos de Reforma Sanitária dos Anos 80: Uma Análise Crítica. Saúde e Sociedade, 5(1), 3-53.

Alcoforado, F. (2010). OS e OSCIP: uma Análise da Abrangência dos Serviços Públicos e do Perfil das Entidades Parceiras em Minas Gerais, São Paulo e Espírito Santo. Revista ADM.MADE, 14(3), 47-65.

Andion, C. (2012). Por uma nova interpretação das mudanças de paradigma na administração pública brasileira. Cadernos EBAPE.BR, 10(1), 1-19.

Arretche, M. (2003). Financiamento federal e gestão local de políticas sociais: o difícil equilíbrio entre regulação, responsabilidade e autonomia. Ciência \& Saúde Coletiva, 2(8), 331-345.

Bahia, L. (2008). As contradições entre o SUS universal e as transferências de recursos públicos para os planos e seguros privados de saúde. Ciência \& Saúde Coletiva, 13(5)

Barbosa, A. P., Tardivo, C. R., Barbosa, E. (2016) Mecanismos de Controle da Gestão do SUS à Luz da Lei Complementar No 141, de 2012. Administração Pública e Gestão Social, 8(1), 66-74.

Barley, S. R. (2007). Corporations, democracy, and the public good. Journal of Management Inquiry, 16(3), 201-215.

Bartley, T. (2011). Transnational Governance as the Layering of Rules: Intersections of Public and Private Standards. Theoretical Inquiries in Law, 12(2), 25-51.

Brasil. Tribunal de Contas da União. Referencial básico de governança aplicável a órgãos e entidades da administração pública. Brasília: TCU, Secretaria de Planejamento, Governança e Gestão, 2014.80 p.

Besley, T., \& Ghatak, M. (2007). Retailing public goods: the economics of corporate social responsibility. Journal of Public Economics, 91(9), 16451663

Blowfield, M. (2005). Corporate Social Responsibility: reinventing the meaning of development. International Affairs, 81(3), 515-524.

Bryman, A. (1989). Research methods and organization studies. London: Unwin Hyman.

Cabral, A. L., \& Cabral, H. L. (2012). Dicotomias entre o público e o privado: agente públicos e privados, o papel do servidor público e a emergência do terceiro setor. Journal of Management Primary Health Care, 3(1), 67-69.

Carter, C., Clegg, S., \& Kornberger, M. (2010). Reframing strategy: Power, politics and accounting. Accounting, Auditing \& Accountability Journal, 23(5), 573-594.

Cavalcante, M. C., \& Luca, M. (2013). Controladoria como instrumento de Governança no Setor Público. Revista de Educação e Pesquisa em Contabilidade, 7(1), 73-90

Cavalcante, P. (2011). Descentralização de políticas públicas sob a ótica neoinstitucional: uma revisão de literatura. Revista de Administração Pública 45(6), 1781-1804.

Child, J. (1997). Strategic choice in the analysis of action: structure organizations and environment. Organization Studies, 18(1), 43-76.

Child, J., \& Rodrigues, S. B. (2011). How Organizations Engage with External Complexity: A Political Action Perspective. Organization Studies, 32(6), 803824.

Clegg, S., Courparsson, D., \& Phillips, N. (2006). Power and Organizations. Londres: Sage.

Desai, M. (2003). Public goods: a historical perspective. In: Kaul, I., Conceição, P., Le Goulven, K., \& Mendoza, R. U. Providing global public goods: managing globalization. New York: Oxford University Press.

Ferlie, E. (2002). Quasi Strategy: Strategic Management in the Contemporary Public Sector. In: Pettigrew, A. M, Thomas, H., \& Whittington, R. Handbook of Strategy and Management. London: Sage.

Ferlie, E., Lynn Jr., L. E., \& Pollitt, C. (2005). The Oxford Handbook of public management. New York: Oxford University Press.

Fontoura, Y., \& Guedes, A. L. (2013). Governança global e transferência de política: influências do Protocolo de Cartagena na Política Nacional de Biossegurança. Revista de Administração Pública, 47(1), 3-23.

Frynas, J. G. (2008). Corporate Social Responsibility and International Development: Critical Assessment. Corporate Governance, 16(4), 274-281. 
Giddens, A. (2003). A constituição da sociedade. $2^{\mathrm{a}}$.ed. São Paulo: Martins Fontes.

Grossi, G. (2013). Public sector governance and accountability. Critical Perspectives on Accounting. 24, 479-487.

Hood, C. (2005). Public Management: the world, the movement, the science. In: Ferlie, E., Lynn Jr., L. E., \& Pollitt, C. The Oxford Handbook of public management, New York: Oxford University Press.

IMF. (2003). The IMF and the good governance. Disponivel em: <www.imf.org/external/np/exr/facts/gov.htm>. Acesso em: 10 dez. 2013.

Jensen, M., \& Meckling, W. (1976). Theory of the firm: managerial behaviour, agency costs and ownership structure. Journal of Financial Economics, 3(2), 305-360.

Jovchelovitch, S., \& Bauer, M. (2000). Narrative interviewing. In: Bauer, M. W., \& Gaskell, G., (eds.) Qualitative Researching with Text, Image and Sound: a Practical Handbook for Social Research. London: Sage. <disponível em: http://eprints.Ise.ac.uk/2633>

Kaufmann, D., Kraay, A., \& Matruzzi, M. (2007). Governance Matters VI: Aggregate and Individual Governance Indicators. Washington: World Bank Policy Research.

Kaul, I., \& Mendoza, R. (2003). Advancing the concept of public goods. In: Kaul, I.,

Conceição, P., Le Goulven, K. \& Mendoza, R. U. Providing global public goods: managing globalization. New York: Oxford University Press.

Kissler, L., \& Heidemann, F. G. (2006). F. G. Governança Pública: novo modelo regulatório para as Relações entre Estado, Mercado e Sociedade. Revista de Administração Pública, 40(3), 479-99.

Kooiman, J. (1993). Modern governance: new government-society interactions. Newbury Park: Sage.

Lindblom, Charles E. (1959). "The Science of Muddling Through", Public Administration Review, 19: 78-88.

Lindblom, Charles E. (1979). "Still Muddling, Not Yet Through", Public Administration Review,39: 517-526.

Marques, M. C. (2007). Aplicação dos princípios da governança corporativa ao sector público. Revista de Administração Contemporânea, 11(2), 11-26.

Martinez, A. L. (1998). Agency Theory na Pesquisa Contábil. Anais do ENANPAD, Foz do Iguaçu, PR, Brasil, 22.

Martins, P. C., Cotta, R. M., Mendes, F., Priore, S., Franceschinni, S., Cazal, M., Batista, R. (2011). De quem é o SUS? Sobre as representações sociais dos usuários do Programa Saúde da Família. Ciência \& Saúde Coletiva, 16(3), 1933-1942.

Matias-Pereira, J.(2010). A governança corporativa aplicada no setor público brasileiro. Administração Pública e Gestão Social, 2(1), 109-134.

Menicucci, T. M. (2007). Público e Privado na política de assistência à saúde no Brasil - atores, processos e trajetória. Rio de Janeiro: Editora Fiocruz.

Menicucci, T. M. (2008). Relação público-privado no sistema de saúde brasileiro: opacidade cognitiva e analítica. Ciência\&Saúde Coletiva, 13(5), 1398-1408.

Mello, G. (2006). Governança corporativa no setor público federal brasileiro. Dissertação de mestrado, Universidade de São Paulo, São Paulo, SP, Brasil.

Milani, C., \& Solinís, G. (2002). Pensar a democracia na governança mundial: algumas pistas para o futuro. In: Milani, C., Arturi, C., \& Solinís, G. (Org.). Democracia e governança mundial: que regulações para o século XXI? Porto Alegre: UFRGS/Unesco, pp. 266-291.

Mintzberg, H. (1996). Managing Government, Governing Management. Harvard Business Review, mai/jun, pp. 75-83.

Moloney, K. (2009). Public administration and governance: a sector-level analysis of World Bank aid. International Review of Administrative Sciences, 75(4), 609-627.

Pedersen, A., Sehested, K., \& Sorensen, E. (2011). Emerging Theoretical Understanding of Pluricentric Coordination in Public Governance. The American Review of Public Administration, 41(4), 375-394.

'Para Almeida (1996, p. 6), a experiência americana de competição (managed competition) no setor sanitário é reinterpretada nas propostas europeias: como o modelo inglês, proposto pelo Working for Patients em 1989; a "Competição Pública", na Suécia (1980); o Relatório Dekker, na Holanda (1987); a medida de contenção de custos na Alemanha (desde os meados dos 80); e a reforma do sistema sanitário na Nova Zelândia (1993); e as propostas de reforma na Itália (1992) e na Espanha (1991).

ii“ "Tinkertoy" é um brinquedo na forma de um kit de construção, composto por um conjunto de peças (discos e varas), de plástico ou madeira, que permite às crianças montar estruturas usando a imaginação.
Pereira, C. (1996). A Política Pública como Caixa de Pandora: Organização de Interesses, Processo Decisório e Efeitos Perversos na Reforma Sanitária Brasileira. Dados, 39(3)

Pettigrew, A. (1992). The character and significance of strategy process research. Strategic Management Journal, 13, 5-16.

Pettigrew, A. (2012). Context and Action in the Transformation of the Firm: A Reprise. Journal of Management Studies, 49(7), 1304-1328.

Pinho, J. A. G. (2016). Reforma do Aparelho do Estado: Limites do Gerencialismo frente ao Patrimonialismo. Sociedade, Contabilidade $e$ Gestão, 11(3), 118-129.

Piola, S., \& Viana, S. (2009). Saúde no Brasil: Algumas questões sobre o Sistema Único de Saúde (SUS). Brasília: CEPAL - Escritório no Brasil, LC/BRS/R.200

Plano Diretor da Reforma do Aparelho do Estado. (1995). Elaborado pelo Ministério da Administração Federal e Reforma do Estado. Brasília, DF: MARE.

Procopiuk, M. (2013). Governança e Interações Multiatores em Redes de Políticas. IN: Procopiuk, M. Políticas Públicas e Fundamentos da Administração. São Paulo: Atlas.

Rampazo, A., Ichikawa, E., \& Carrieri, A. (2014). A influência do "Mundo dos Negócios" na governança ambiental global. Revista de Ciências da Administração, 16(40), 75-89.

Rezende, F. C. (2008). The Implementation Problem of New Public Management Reforms: the dilemma of control and the theory of sequential failure. International Public Management Review, 9(2), 40-65.

Saliba, N., Moimaz, S., Ferreira, N., Custódio, L. (2009). Conselhos de saúde: conhecimento sobre as ações de saúde. Revista de Administração Pública, 43(6), 1369-1378.

Santos, C., \& Carrion, R. S. M. (2011). Sobre a governança da cooperação internacional para o desenvolvimento: atores, propósitos e perspectivas. $R A P, 45(6), 1847-68$

Santos, I., Ugá, M., \& Porto, S. (2008). O mix público-privado no sistema de saúde brasileiro: financiamento, oferta e utilização dos serviços de saúde. Ciência e Saúde Coletiva, 13(5), 1431-1440.

Sauerbronn, F. F., \& Faria, A. (2011). Agência em estratégia: conectando prática social e codeterminação. RAM, 12(6), 49-75.

Secchi, L. (2009). Modelos Organizacionais e Reformas da Administração Pública. Revista de Administração Pública, 43(2), 347-369.

Silva, J. A. F., Pessoa, E. B, Batista, E. C., \& Scaccabarozzi, N. C.(2011) Princípios da Governança no Setor Público: Um Estudo no Tribunal de Contas do Estado do Ceará. Anais do ENANPAD, Rio de Janeiro, RJ, Brasil, 35.

Simão, L. A. S., Guedes, A. L., \& Nieto, A. (2017). Inserção Internacional de Angola: Intervenções e Interferências Externas e suas Implicações para Governança e Gestão Pública. Sociedade, Contabilidade e Gestão, 12(1) 111-129.

Slomski, V. (2007). Controladoria e governance na gestãopublica. 1. ed. São Paulo: Atlas.

Slomski, W., Mello, G. R., Tavares Filho, F., \& Macedo, F. (2008). Governança Corporativa e Governança na Gestão Pública. São Paulo: Atlas.

Smith, A. (2010). Governança de Múltiplos Níveis: o que é e como pode ser estudada. In: Peters, B. G., \& Pierre, S. Administração Pública: coletânea, Cap. 28. São Paulo: UNESP.

Sorensen, E. (2014). Conflict as driver of pluricentric coordination. Planning Theory, 13(2), 152-169.

Stivers, C. (2009). The Ontology of Public Space: Grounding Governance in Social Reality. American Behavioral Scientist, 52(7), 1095-1108.

Stoker, G. (1998). Governance as Theory: five propositions. Oxford: Blackwell Publishing.

Thomas, M. A. (2010). What Do the Worldwide Governance Indicators Measure? European Journal of Development Research, 22(1), 31-54.

A autora agradece ao CNPQ e à FAPERJ pelo apoio financeiro concedido.

iiisegundo os autores Child (1997) e Child e Rodrigues (2011), a expressão 'organizações como atores', e mesmo qualquer referência a uma organização, não implica em uma reificação das organizações, mas sim em uma abreviação para denominar os atores dentro das organizações que tomam decisões fundamentais que determinam as ações e comportamentos de organizações. Para os autores os termos 'ator' e 'tomador de decisões' são usados como sinônimos. 